\title{
Factors affecting blood pressure in patients with hypertension and subclinical hypothyroidism
}

\author{
Anastasiia 0. Radchenko $₫$, Olena V. Kolesnikova ${ }^{\circledR}$ \\ L.T. Mala Therapy National Institute of the National Academy of Medical Sciences of Ukraine, Kharkiv, Ukraine
}

\begin{abstract}
Background: The aim our study was to identify factors affecting blood pressure in patients with hypertension (HTN) and subclinical hypothyroidism (SH).

Material and methods: One hundred and thirty-eight patients aged from 25 to 59 years were examined and divided into control group $(\mathrm{n}=30)$, euthyroid patients with HTN $(\mathrm{n}=45)$ and patients with HTN in combination with SH $(n=63)$. The levels of tumor necrosis factor- $\alpha$, C-reactive protein, total hydroperoxide content, total antioxidant activity, total superoxide dismutase activity and sirtuin 1 were measured in addition to complete blood count and routine biochemical tests. The Kruskal-Wallis $\mathrm{H}$ test was used to test whether there was a significant difference between the independent and its dependent variables.

Results: Fewer factors affected systolic and diastolic blood pressure in patients with HTN and SH compared with euthyroid patients. These included age, waist circumference, insulin, triglycerides, very high-density lipoprotein cholesterol, and TAA. The opposite results were found in relation to the increase in pulse pressure: significant effects of gender, hemoglobin, alkaline phosphatase were observed in patients with SH and only the level of ACT had a significant influence in euthyroid patients.
\end{abstract}

Conclusions: Factors associated with blood pressure and their overall number differed among patients with $\mathrm{SH}$ and HTN compared with euthyroid patients with HTN. Such results may be due to changes in anthropometric parameters, metabolic profile and oxidative status in patients with concomitant $\mathrm{SH}$.

Key words: arterial hypertension; subclinical hypothyroidism; blood pressure; oxidative stress markers; inflammation markers

\section{Introduction}

Hypertension (HTN) is among the most common diseases in the population of developed countries and the prevalence of $\mathrm{HTN}$ ranges from $33.1 \%$ to 45.4\% [1]. In Ukraine the prevalence of hypertension increases over the years, along with the risk factors for cardiovascular diseases (CVD) [2]. The National Health and Nutrition Examination Survey (NHANES) reports that $50 \%$ of hypertensive patients do not reach the target blood pressure (BP) levels despite therapeutic measures in the presence of hypertension, that leads to an increase in overall and CVD mortality [3]. Increased systolic blood pressure

Address for correspondence: Anastasiia 0. Radchenko, L.T. Mala NIT NAMSU, 2 a, Lyubovi Maloy ave., 61039 Kharkiv, Ukraine; e-mail: anastasha.radchenko@gmail.com

This article is available in open access under Creative Common Attribution-Non-Commercial-No Derivatives 4.0 International (CC BY-NC-ND 4.0) license, allowing to download articles and share them with others as long as they credit the authors and the publisher, but without permission to change them in any way or use them commercially 
(SBP) is the most important factor in global disability and overall mortality for both sexes. Between 2007 and 2017, the number of disability-adjusted life-years (DALYs) due to HTN increased by $20 \%$ [4]. Therefore, it is extremely important to identify in advance the factors that can lead to increased blood pressure and further increase in cardiovascular risk (CVR) among young and middle-aged people with HTN.

At the same time, the number of diagnosed cases of subclinical hypothyroidism ( $\mathrm{SH}$ ) has increased due to the new diagnostic methods [5]. It is known that HTN and $\mathrm{SH}$ have common risk factors for CVD, which may increase the severity of hypertension in patients with this comorbid pathology. Common CVR factors in such patients include disorders of the lipid profile, increased arterial stiffness, elevated C-reactive protein and diastolic hypertension [6]. In a number of studies, serum thyroid-stimulating hormone (TSH) levels were positively correlated (adjusted by age and gender) with lipid parameters, glucose, insulin, BP, and waist circumference (WC) [7]. There are many studies examining the effects of various exogenous and endogenous factors on elevated BP in patients with HTN $[8,9]$, but data on the study of factors associated with BP in patients with combined HTN and SH have not been found. That is why finding factors affecting systolic, diastolic and pulse blood pressure by investigating peculiarities of anthropometric, clinical and biochemical parameters in patients with HTN and SH became the aim of our study.

\section{Material and methods}

The study included 138 patients (the age 25-59 years, women $54.3 \%$ ) with low/moderate CVR who underwent outpatient or inpatient treatment at the L.T. Mala Therapy National Institute of the National Academy of Medical Sciences of Ukraine (L.T. Mala NIT NAMSU) in Ukraine from 2019 to 2020 and signed the informed consent to participate in the study. The research protocol was approved at a meeting of the Ethics Commission of the L.T. Mala NIT NAMSU. All patients were divided into 3 groups randomized by age and gender: group 1-30 healthy volunteers (hereinafter - controls); group 2-45 euthyroid patients with stage 1-2 grade 1-2 HTN and low/moderate CVR (hereinafter - HTN without $\mathrm{SH}$ ) and with signs of autoimmune thyroiditis (AIT); group 3-63 patients with stage $1-2$ grade $1-2$ HTN and low/moderate CVR in combination with $\mathrm{SH}$ and with signs of AIT (hereinafter - HTN with
$\mathrm{SH})$. The diagnosis of hypertension was made on the basis of 2020 International Society of Hypertension Global Hypertension Practice Guidelines [10]. All patients received standard therapy for HTN. The diagnosis of AIT was verified by ultrasound examination of the thyroid gland, determination of thyroperoxidase antibody and thyroid function in all patients. The presence of $\mathrm{SH}$ in patients was assessed according to the 2013 European Thyroid Association clinical guidelines for $\mathrm{SH}$ [11].

Physical examination of patients included measurements of height, body weight, waist circumference (WC) and hip circumference (HC), body mass index (BMI) calculation and waist-to-hip ratio (WC/HC) calculation. Office BP was measured in accordance with 2020 International Society of Hypertension Global Hypertension Practice Guidelines [10]. Pulse BP (PBP) was evaluated as the difference between SBP and diastolic BP (DBP).

Complete blood test was done in all patients. Lipid metabolism was assessed by total cholesterol (TC), triglycerides, low density lipoprotein cholesterol (LDL-C), very low density lipoprotein cholesterol (VLDL-C) and high density lipoprotein cholesterol (HDL-C). Carbohydrate metabolism was assessed by measuring blood glucose, glycated hemoglobin $\left(\mathrm{HbA}_{1 \mathrm{c}}\right)$ and insulin levels. Insulin resistance (IR) was determined by the HOMA-IR calculation. Liver function was assessed by measuring the levels of aspartate aminotransferase (AST), alanine aminotransferase (ALT) and alkaline phosphatase (AP). Renal function was assessed by measuring the levels of creatinine, uric acid, total protein, albumin and glomerular filtration rate (GFR) calculation. The inflammatory activity was evaluated by the levels of tumor necrosis factor- $\alpha$ (TNF- $\alpha$ ) and C-reactive protein (CRP). The state of the prooxidant system was evaluated by the levels of total hydroperoxide (THP) content, and the state of antioxidant protection system - by total antioxidant activity (TAA), THP to TAA ratio (THP/TAA) calculation, total superoxide dismutase activity (T-SOD). Sirtuin 1 (SIRT1) was also measured as one of the oxidative stress (redox stress) indicator.

\section{Statistical analysis}

The statistical processing of the obtained data was carried out using IBM SPSS version 19.0 software. Since most of the variables were not normally distributed, the results are presented in the form of the median $(\mathrm{Me})$ and interquartile ranges -25 (Q1) and 75 (Q3) percentiles - Me (Q1; Q3). The non-parametric Mann-Whitney $U$ test was used to perform the comparison of indicators between 
groups. The Kruskal-Wallis $\mathrm{H}$ test was used to test whether there was a significant difference between the independent variable group and its dependent variable. Significance was set at a $\mathrm{p}$ value of $<0.05$ in all cases.

\section{Results}

In patients with HTN regardless of the $\mathrm{SH}$ presence there was a higher proportion of lymphocytes $(p=0.008$ for the group of euthyroid patients with hypertension and $\mathrm{p}<0.001$ for the group with combined HTN and SH compared with the controls), higher red blood cell count $(\mathrm{p}<0.001$; $\mathrm{p}<0.001)$, hemoglobin $(\mathrm{p}<0.001 ; \mathrm{p}=0.009)$, hematocrit $(\mathrm{p}<0.001 ; \mathrm{p}=0.005)$, red cell distribution width $(\mathrm{RDW})(\mathrm{p}<0.001 ; \mathrm{p}<0.001)$ and significantly lower platelet count $(\mathrm{p}=0.017 ; \mathrm{p}=0.010)$ respectively. Patients with HTN and SH also had a signifi- cantly higher erythrocyte sedimentation rate (ESR) compared to controls $(\mathrm{p}=0.014)$, which together with an increase in the proportion of lymphocytes may indicate an increase in the activity of inflammatory processes in this category of patients. Significantly lower levels of hemoglobin $(p=0.022)$ and mean corpuscular volume (MCV) $(\mathrm{p}=0.002)$ were observed in patients with HTN in case of concomitant $\mathrm{SH}$.

Carbohydrate and lipid profile were worse in patients with HTN and SH (Tab. 1). The exceptions were glucose and LDL-C levels, which did not differ significantly in patients with HTN depending on the $\mathrm{SH}$ presence. In contrast to patients with HTN and $\mathrm{SH}, \mathrm{HDL}-\mathrm{C}$ levels in euthyroid patients with HTN did not differ significantly from controls.

Liver dysfunction was exacerbated in patients with HTN and was significantly more pronounced in patients with HTN and concomitant SH (Tab. 2). There were no significant differences only in AP

Table 1. Characteristics of lipid and carbohydrate profile in patients within different groups

\begin{tabular}{|c|c|c|c|c|}
\hline Indicators & $\begin{array}{l}\text { Control group } \\
\quad(\mathrm{n}=30)\end{array}$ & $\begin{array}{l}\text { HTN group } \\
(\mathrm{n}=45)\end{array}$ & $\begin{array}{l}\text { HTN + SH group } \\
(\mathrm{n}=63)\end{array}$ & $\begin{array}{l}\text { p1 } \\
\text { p2 } \\
\text { p3 }\end{array}$ \\
\hline Glucose $[\mathrm{mmol} / \mathrm{L}]$ & $4.94[4.79 ; 5.23]$ & $5.29[4.97 ; 5.60]$ & $5.63[5.07 ; 5.82]$ & $\begin{array}{c}0.004 \\
<0.001 \\
>0.05\end{array}$ \\
\hline $\mathrm{HbA}_{1 \mathrm{c}}(\%)$ & $5.14[4.90 ; 5.23]$ & $5.19[5.07 ; 5.58]$ & $5.91[5.76 ; 6.17]$ & $\begin{array}{c}0.028 \\
<0.001 \\
<0.001\end{array}$ \\
\hline Insulin $[\mu \mathrm{IU} / \mathrm{mL}]$ & $10.46[9.45 ; 11.16]$ & $18.28[12.51 ; 25.75]$ & $22.87[17.43 ; 30.29]$ & $\begin{array}{c}<0.001 \\
<0.001 \\
0.023\end{array}$ \\
\hline HOMA IR & $2.34[2.18 ; 2.66]$ & $4.02[2.96 ; 6.63]$ & $5.85[4.26 ; 7.80]$ & $\begin{array}{c}<0.001 \\
0.000 \\
0.003\end{array}$ \\
\hline $\mathrm{TC}[\mathrm{mmol} / \mathrm{L}]$ & $4.54[4.30 ; 5.12]$ & $5.55[4.77 ; 6.22]$ & $5.90[5.34 ; 6.63]$ & $\begin{array}{c}<0.001 \\
0.000 \\
0.043\end{array}$ \\
\hline TG $[\mathrm{mmol} / \mathrm{L}]$ & $0.87[0.77 ; 1.17]$ & $1.16[0.88 ; 1.75]$ & $1.51[1.17 ; 2.15]$ & $\begin{array}{c}0.009 \\
<0.001 \\
0.011\end{array}$ \\
\hline VLDL-C [mmol/L] & $0.42[0.32 ; 0.59]$ & $0.55[0.40 ; 0.84]$ & $0.77[0.55 ; 0.99]$ & $\begin{array}{c}0.007 \\
<0.001 \\
0.004\end{array}$ \\
\hline $\mathrm{HDL}-\mathrm{C}[\mathrm{mmol} / \mathrm{L}]$ & $1.39[1.19 ; 1.54]$ & $1.26[1.09 ; 1.45]$ & $1.11[0.94 ; 1.26]$ & $\begin{array}{l}>0.05 \\
<0.001 \\
<0.001\end{array}$ \\
\hline LDL-C [mmol/L] & $2.62[2.47 ; 3.08]$ & $3.68[2.80 ; 4.38]$ & $4.02[3.22 ; 4.54]$ & $\begin{array}{l}<0.001 \\
<0.001 \\
>0.05\end{array}$ \\
\hline
\end{tabular}

p1 - between the controls and the group of euthyroid patients with HTN; p2 - between the controls and HTN + SH group of HTN and SH; p3 - between the groups of HTN and HTN + SH; HTN — hypertension; SH — subclinical hypothyroidism; $\mathrm{HbA}_{1 \mathrm{c}}$ - glycated hemoglobin; TC — total cholesterol; TG — triglycerides; VLDL-C — very low density lipoprotein cholesterol; HDL-C — high density lipoprotein cholesterol; LDL-C — low density lipoprotein cholesterol 
Table 2. Comparative assessment of liver and kidney function in patients within different groups

\begin{tabular}{|c|c|c|c|c|}
\hline Indicators & $\begin{array}{l}\text { Control group } \\
\quad(\mathrm{n}=30)\end{array}$ & $\begin{array}{l}\text { HTN group } \\
(\mathrm{n}=45)\end{array}$ & $\begin{array}{c}\text { HTN + SH group } \\
(\mathrm{n}=63)\end{array}$ & $\begin{array}{l}\text { p1 } \\
\text { p2 } \\
\text { p3 }\end{array}$ \\
\hline AST [U/L] & $23[19 ; 28]$ & $25[22 ; 31]$ & $31[25 ; 37]$ & $\begin{array}{c}0.041 \\
<0.001 \\
0.005\end{array}$ \\
\hline ALT [U/L] & $23[19 ; 25]$ & $29[24 ; 36]$ & $38[30 ; 47]$ & $\begin{array}{l}<0.001 \\
<0.001 \\
<0.001\end{array}$ \\
\hline $\mathrm{AP}[\mathrm{U} / \mathrm{L}]$ & 1222 [1149; 1333] & $1431[1210 ; 1716]$ & $1525[1355 ; 1701]$ & $\begin{array}{l}<0.001 \\
<0.001 \\
>0.05\end{array}$ \\
\hline Uric acid $[\mu \mathrm{mol} / \mathrm{L}]$ & $255[229 ; 301]$ & $275[220 ; 322]$ & $287[266 ; 315]$ & $\begin{array}{c}>0.05 \\
0.013 \\
>0.05\end{array}$ \\
\hline Creatinine $[\mu \mathrm{mol} / \mathrm{L}]$ & $75[67 ; 83]$ & 87 [78; 103] & $91[78 ; 101]$ & $\begin{array}{l}<0.001 \\
<0.001 \\
>0.05\end{array}$ \\
\hline Total protein $[\mathrm{g} / \mathrm{L}]$ & $74[71 ; 78]$ & 77 [73; 79] & $74[71 ; 76]$ & $\begin{array}{l}>0.05 \\
>0.05 \\
<0.001\end{array}$ \\
\hline Albumin $[g / L]$ & $43.5[41.0 ; 47.3]$ & $44.4[41.8 ; 47.3]$ & $43.2[41.3 ; 44.6]$ & $\begin{array}{c}>0.05 \\
>0.05 \\
\mathbf{0 . 0 2 7}\end{array}$ \\
\hline
\end{tabular}

p1 - between the controls and the group of euthyroid patients with HTN; p2 - between the controls and HTN + SH group of HTN and SH; 33 - between the groups of HTN and HTN + SH; HTN — hypertension; SH — subclinical hypothyroidism; AST — aspartate aminotransferase; ALT — alanine aminotransferase; AP — alkaline phosphatase

levels in patients with HTN depending on the presence of SH. The tendency to deterioration of renal function, manifested in an increase in creatinine, uric acid levels and a decrease in total protein levels due to a serum albumin levels decrease, was observed in patients with a combined course of HTN and SH.

The severity of inflammatory processes increased in patients with HTN with the addition of SH that was shown by increased levels of TNF $(p<0.001)$ and CRP $(\mathrm{p}<0.001)$.

Disorders of redox processes were also more noticeable with the addition of $\mathrm{SH}$ in patients with HTN (Tab. 3). This imbalance was manifested in a decrease in antioxidant enzymes levels (T-SOD) and an increase in the severity of oxidative processes, markers of which were the increased levels of THP and the THP to TAA ratio. SIRT1, in contrast, was significantly higher in patients with combined HTN and $\mathrm{SH}$ compared to euthyroid patients with HTN.

Measurement of anthropometric parameters revealed an increase in BMI as well as a decrease in the $\mathrm{WC} / \mathrm{HC}$ ratio due to a significant increase in HC in patients with HTN and SH compared with euthyroid patients with HTN. That means that the tendency to the obesity development was accompanied by an improvement in the $\mathrm{WC} / \mathrm{HC}$ ratio in patients with HTN and SH (Tab. 4). Measurement of the office BP revealed an increase in SBP and DBP in patients with HTN regardless of the SH presence compared with controls. Only patients with HTN and SH had an increase in PBP levels compared to the control group, that means there was a tendency to increase PBP levels in patients with concomitant $\mathrm{SH}$.

The search for factors of elevated BP $(\geq 130 / 85$ $\mathrm{mm} \mathrm{Hg}$ ) among the studied indicators in euthyroid patients with HTN revealed that BP was affected by gender $(p=0.029$ for SBP and $p=0.007$ for $\mathrm{DBP})$, hypertriglyceridemia ( $\mathrm{p}=0.040$ for SBP and $p=0.015$ for DBP), increase in CRP levels $(p=0.023$ for DBP), renal dysfunction with decreased GFR as an indicator $(\mathrm{p}=0.023$ for DBP $)$, overweight and obesity ( $p=0.017$ for SBP and $p=0.020$ for DBP), the presence of carbohydrate profile disorders in the form of increased insulin levels ( $p=0.001$ for SBP and $\mathrm{p}=0.001$ for DBP). In addition, markers of liver dysfunction (ALT: $\mathrm{p}=0.006$ for SBP and $\mathrm{p}=0.022$ for DBP; AST: $p=0.008$ for SBP), redox balance (THP/TAA: $\mathrm{p}=0.039$ for SBP; THP: $\mathrm{p}=0.010$ for $\mathrm{DBP})$, and red blood cells $(\mathrm{p}=0.027$ for SBP and $p=0.003$ for DBP) also contributed to elevated levels of SBP and DBP in patients with HTN. 
Table 3. Comparative evaluation of markers of redox processes in patients within different groups

\begin{tabular}{|c|c|c|c|c|}
\hline Indicators & $\begin{array}{l}\text { Control group } \\
\qquad(\mathrm{n}=30)\end{array}$ & $\begin{array}{l}\text { HTN group } \\
(\mathrm{n}=45)\end{array}$ & $\begin{array}{c}\text { HTN + SH group } \\
(\mathrm{n}=63)\end{array}$ & $\begin{array}{l}\text { p1 } \\
\text { p2 } \\
\text { p3 }\end{array}$ \\
\hline T-SOD [U/mL] & $54.55[50.02 ; 59.87]$ & $48.49[46.12 ; 51.49]$ & 46.16 [44.20; 49.44] & $\begin{array}{c}<0.001 \\
<0.001 \\
0.002\end{array}$ \\
\hline THP $[\mu \mathrm{mol} / \mathrm{L}]$ & $89.96[72.98 ; 113.14]$ & $102.43[89.07 ; 145.45]$ & 152.21 [125.90; 167.76] & $\begin{array}{l}0.030 \\
<0.001 \\
<0.001\end{array}$ \\
\hline TAA [ $\mu \mathrm{mol}$ trolox equivalent] & $590.23[570.75 ; 620.26]$ & $539.35[419.91 ; 597.85]$ & $494.14[415.58 ; 546.01]$ & $\begin{array}{c}0.005 \\
<0.001 \\
>0.05\end{array}$ \\
\hline THP/ & $0.16[0.12 ; 0.19]$ & $0.19[0.16 ; 0.30]$ & $0.30[0.24 ; 0.40]$ & $\begin{array}{l}0.002 \\
<0.001 \\
<0.001\end{array}$ \\
\hline SIRT1 [ng/mL] & $5.34[3.75 ; 6.76]$ & $3.74[3.59 ; 4.14]$ & $4.36[4.07 ; 4.88]$ & $\begin{array}{c}<0.001 \\
0.025 \\
<0.001\end{array}$ \\
\hline
\end{tabular}

p1 — between the controls and the group of euthyroid patients with HTN; p2 - between the controls and HTN + SH group of HTN and SH; p3 - between the groups of HTN and HTN + SH; HTN — hypertension; SH — subclinical hypothyroidism; T-SOD — total superoxide dismutase activity; THP — total hydroperoxide; TAA — total antioxidant activity; SIRT1 - sirtuin 1

Table 4. Comparative assessment of anthropometric indicators and office blood pressure in patients within different groups

\begin{tabular}{|c|c|c|c|c|}
\hline Indicators & $\begin{array}{l}\text { Control group } \\
\quad(n=30)\end{array}$ & $\begin{array}{l}\text { HTN group } \\
(\mathrm{n}=45)\end{array}$ & $\begin{array}{l}\text { HTN + SH group } \\
\quad(n=63)\end{array}$ & $\begin{array}{l}\mathrm{p} 1 \\
\mathrm{p} 2 \\
\mathrm{p} 3\end{array}$ \\
\hline WC [cm] & $80.0[77.6 ; 87.5]$ & $93.5[80.4 ; 99.3]$ & $93.0[85.9 ; 100.1]$ & $\begin{array}{l}<0.001 \\
<0.001 \\
>0.05\end{array}$ \\
\hline $\mathrm{HC}[\mathrm{cm}]$ & $98.0[95.4 ; 103.3]$ & 101.0 [97.9; 105.0$]$ & $105.0[101.5 ; 110.8]$ & $\begin{array}{c}0.032 \\
<0.001 \\
0.002\end{array}$ \\
\hline WC/HC & $0.8[0.8 ; 0.9]$ & $0.9[0.9 ; 1.0]$ & $0.9[0.8 ; 0.9]$ & $\begin{array}{c}<0.001 \\
0.021 \\
0.025\end{array}$ \\
\hline BMI $\left[\mathrm{kg} / \mathrm{m}^{2}\right]$ & $23.2[21.6 ; 24.4]$ & $27.2[25.2 ; 29.4]$ & $28.6[27.1 ; 30.3]$ & $\begin{array}{c}<0.001 \\
<0.001 \\
0.007\end{array}$ \\
\hline $\mathrm{SBP}[\mathrm{mm} \mathrm{Hg}]$ & $116[114 ; 120]$ & $130[120 ; 137]$ & $130[120 ; 139]$ & $\begin{array}{l}<0.001 \\
<0.001 \\
>0.05\end{array}$ \\
\hline $\mathrm{DBP}[\mathrm{mm} \mathrm{Hg}]$ & $74[70 ; 77]$ & $80[75 ; 90]$ & 83 [76; 90] & $\begin{array}{l}<0.001 \\
<0.001 \\
>0.05\end{array}$ \\
\hline PBP [mm Hg] & $45[42 ; 45]$ & $46[40 ; 53]$ & $48[40 ; 54]$ & $\begin{array}{c}>0.05 \\
0.021 \\
>0.05\end{array}$ \\
\hline
\end{tabular}

p1 - between the controls and the group of euthyroid patients with HTN; p2 - between the controls and HTN + SH group of HTN and SH; p3 - between the groups of HTN and HTN + SH; HTN — hypertension; SH — subclinical hypothyroidism; WC — waist circumference; HC — hip circumference; BMI — body mass index; SBP — systolic blood pressure; $\mathrm{DBP}$ — diastolic blood pressure; $\mathrm{PBP}$ - pulse BP

There were fewer factors that effected SBP and DBP significantly in patients with HTN who had concomitant SH. They included age $(p=0.004$ for
SBP and $p=0.002$ for DBP), insulin ( $p=0.031$ for SBP and $\mathrm{p}=0.026$ for DBP), TG ( $\mathrm{p}=0.008$ for SBP and $\mathrm{p}=0.031$ for DBP), LDL-C ( $\mathrm{p}=0.040$ for 
SBP), TAA ( $p=0.046$ for DBP $)$ and WC $(p=0.007$ for DBP). On the contrary, only the level of AST $(\mathrm{p}=0.003)$ significantly affected the increase in PBP ( $>40 \mathrm{~mm} \mathrm{Hg}$ ) in euthyroid patients with HTN, while in patients with combined HTN and SH the influence of gender $(\mathrm{p}=0.030)$, hemoglobin $(\mathrm{p}=0.034)$ and $\mathrm{AP}(\mathrm{p}=0.007)$ were detected.

\section{Discussion}

According to the available literature, thyroid disorders are often associated with the development of anemia [12]. In our study there was a tendency to increase the risk of anemia in patients with the emergence of $\mathrm{SH}$, which is manifested in a decrease in MCV and hemoglobin. Similar results were shown in the meta-analysis made by Wopereis et al. (2018, $\mathrm{n}=25,466)[13]$.

Metabolic disorders caused by the presence of $\mathrm{SH}$ in our patients were accompanied by the similar disorders common among patients with HTN, which led to an even worse metabolic profile in patients with combined pathology. Other authors also showed that lipid and carbohydrate profile disorders were more pronounced even in patients with high normal thyroid function $(\mathrm{TSH}>2.93 \mathrm{mIU} / \mathrm{L}$, that is $>90^{\text {th }}$ percentile $)$ and moderate $\mathrm{SH}(\mathrm{TSH}<9.9$ $\mathrm{IU} / \mathrm{mL})[14,15]$.

Adverse effects of existing $\mathrm{SH}$ on liver and kidney function were observed in patients with combined HTN and SH in current study. The following results are consistent with the data from other researchers, namely that subclinical thyroid dysfunction is dose-dependently associated with the development of NAFLD [16] and high, even within normal, levels of TSH are independent predictors of NASH [17], uric acid metabolism in patients with $\mathrm{SH}$ is associated with thyroid function and HOMA-IR, which is often elevated in these patients [18], serum creatinine levels in $\mathrm{SH}$ patients are associated with changes in TSH [19], and $\mathrm{SH}$ is a significant independent predictor of microalbuminuria [20].

Low-grade inflammation and dysfunction of oxidative and antioxidant processes, which underlie the development of many chronic non-communicable diseases and are common in patients with $\mathrm{SH}$ [21-24], were found in patients with a combined course of hypertension and $\mathrm{SH}$ in our study. Interestingly, SIRT1, which plays a protective role in the development of oxidative stress [25], was elevated in patients with HTN and SH. The probable cause of increased SIRT1 levels accompanied by the deterioration of oxidative stress markers may be the associa- tion between the synthesis of TSH and SIRT1 [26]. That is why SIRT1 may have protective role in this category of patients.

Contradictory data on changes in anthropometric parameters were obtained in our study in people with SH compared with euthyroid patients with HTN. Higher values of BMI, which is a CVR factor, together with lower waist to hip ratio due to $\mathrm{HC}$, which indicates an improvement in the cardioprotective effect, were seen in patients with concomitant SH. The results of other researchers generally indicate a deterioration of anthropometric data in patients with $\mathrm{SH}$, namely an increased risk of being overweight and central obesity $[15,27,28]$.

We found that BP in euthyroid patients with HTN was affected by indicators that are common risk factors for $\operatorname{CVD}[9,29,30]$. Similar data were obtained in the Hordaland Health Study [8]. If the association with these CVD risk factors on blood pressure is clear, the role of ALT and AST is still unclear, despite the prevalence of such disorders in patients with HTN [31], it is probably associated with metabolism of drugs for HTN in these patients. Oxidative stress processes are among the main mechanisms of HTN development [21], so it is not surprising that the increase in markers of oxidative processes affects BP level in patients with HTN. Red blood cell dysfunction is also closely associated with HTN, stroke and other cardiovascular diseases [32], which can explain the influence of elevated red blood cell levels on SBP and DBP in patients with HTN.

In contrast to euthyroid patients with HTN, in the group of our patients with combined course of hypertension and $\mathrm{SH}$ the number of factors associated with SBP and DBP was significantly lower. A possible cause of such changes may be the existence of the typical disorders in $\mathrm{SH}$, which leads to an increase in the impact of certain factors on BP and, as a consequence, reduce the impact of other indicators. It can be assumed that the reasons for the increase in the influence of certain markers in patients with $\mathrm{SH}$ are probably:

- high prevalence and severity of hyperinsulinemia in patients with $\mathrm{SH}$ [14];

- increase in prevalence and severity of existing lipid disorders, especially hypertriglyceridemia, with the addition of $\mathrm{SH}[15,33]$;

- increase in obesity prevalence and grade in $\mathrm{SH}$, which is associated with changes in WC and HC [28];

- violation oxidative state processes in SH [22].

Despite the effect of hyperinsulinemia on SBP and DBP and significantly higher HOMA-IR in patients with $\mathrm{SH}$ compared to euthyroid patients with 
HTN, the increase in insulin levels in this category of patients (with HTN and $\mathrm{SH}$ ) did not result in insulin resistance that could affect the emergence of increased BP. Probable cause of this may the lack of pronounced violations as a result of early-stage hypertension and mild SH (TSH up to $10 \mu \mathrm{IU} / \mathrm{mL}$ ). Thus, the effect of HOMA-IR on SBP and DBP was not observed.

It is also noteworthy that THP was not affecting $\mathrm{BP}$ in SH patients and, on the contrary, the level of TAA as an additional marker of oxidative state associate with elevated DBP despite a significant increase in THP in patients with HTN and SH compared with euthyroid patients with HTN.

The level of PBP in patients with $\mathrm{SH}$ was associate with more factors than in euthyroid patients with HTN, namely by gender, hemoglobin, AP levels, which does not contradict the results of other researchers: PBP levels are indirectly associated with AP via arterial stiffness $[34,35]$ and independently associated with anemia [36] and worse metabolic profile in women [37]. Moreover, patients with a combined course of HTN and SH tend to have anemia and liver abnormalities, which makes the effect of hemoglobin and AP levels more noticeable in this category of patients. In addition, gender in patients with $\mathrm{SH}$ is associated with a number of factors that may affect blood pressure, that are a high risk of developing NAFLD in men [38], worse noninvasive visceral fat indices in women [39], higher incidence of metabolic syndrome and its components [40].

\section{Conclusions}

In our study factors associated with blood pressure and their overall number differed among patients with subclinical hypothyroidism and arterial hypertension compared with euthyroid patients with arterial hypertension. Such results may be due to changes in anthropometric parameters, metabolic profile and oxidative status in patients with concomitant subclinical hypothyroidism.

\section{Author contributions}

A.O.R. collected data, performed statistical analysis and contributed to manuscript writing. O.V.K. designed the study, collected data and contributed to manuscript writing.

\section{Conflicts of interest}

There is no conflict of interest with any financial organization regarding the material discussed in the present article.

\section{Funding}

The authors received no financial support for the research, authorship, and/or publication of this article.

\section{References}

1. Mills KT, Stefanescu A, He J. The global epidemiology of hypertension. Nat Rev Nephrol. 2020; 16(4): 223-237, doi: 10.1038/ s41581-019-0244-2, indexed in Pubmed: 32024986.

2. Dyachuk DD, Moroz GZ, Gidzinskaya IM, et al. [Prevalence of risk factors for cardiovascular diseases in Ukraine: a modern view of the problem]. Ukrain J Cardiol. 2018; 1: 91-101.

3. Zhou D, Xi Bo, Zhao M, et al. Uncontrolled hypertension increases risk of all-cause and cardiovascular disease mortality in US adults: the NHANES III Linked Mortality Study. Sci Rep. 2018; 8(1): 9418, doi: 10.1038/s41598-018-27377-2, indexed in Pubmed: 29925884.

4. GBD 2017 Risk Factor Collaborators, GBD 2016 Risk Factors Collaborators. Global, regional, and national comparative risk assessment of 84 behavioural, environmental and occupational, and metabolic risks or clusters of risks, 1990-2016: a systematic analysis for the Global Burden of Disease Study 2016. Lancet. 2017; 390(10100): 1345-1422, doi: 10.1016/S0140-6736(17)323668, indexed in Pubmed: 28919119.

5. Dey A, Kanneganti V, Das D. A study of the cardiac risk factors emerging out of subclinical hypothyroidism. J Family Med Prim Care. 2019; 8(7): 2439-2444, doi: 10.4103/jfmpc. jfmpc_348_19, indexed in Pubmed: 31463273.

6. Decandia F. Risk factors for cardiovascular disease in subclinical hypothyroidism. Ir J Med Sci. 2018; 187(1):39-43, doi: $10.1007 /$ s11845-017-1617-9, indexed in Pubmed: 28493136.

7. Iervasi G, Pingitore A, Gerdes AM, Razvi S. ed. Thyroid and Heart: A Comprehensive Translational Essay. Springer Nature, New York 2020.

8. Kringeland E, Tell GS, Midtbø H, et al. Factors associated with increase in blood pressure and incident hypertension in early midlife: the Hordaland Health Study. Blood Press. 2020; 29(5): 267-275, doi: $10.1080 / 08037051.2020 .1762070$, indexed in Pubmed: 32400220.

9. Ferguson TS, Younger-Coleman NOM, Tulloch-Reid MK, et al. High-Sensitivity C-Reactive Protein is Related to Central Obesity and the Number of Metabolic Syndrome Components in Jamaican Young Adults. Front Cardiovasc Med. 2014; 1: 12, doi: 10.3389/fcrm.2014.00012, indexed in Pubmed: 26664862.

10. Unger T, Borghi C, Charchar F, et al. 2020 International Society of Hypertension Global Hypertension Practice Guidelines. Hypertension. 2020; 75(6): 1334-1357, doi: 10.1161/HYPERTENSIONAHA.120.15026, indexed in Pubmed: 32370572.

11. Pearce SHS, Brabant G, Duntas LH, et al. 2013 ETA Guideline: Management of Subclinical Hypothyroidism. Eur Thyroid J. 2013; 2(4): 215-228, doi: 10.1159/000356507, indexed in Pubmed: 24783053.

12. Szczepanek-Parulska E, Hernik A, Ruchała M. Anemia in thyroid diseases. Pol Arch Intern Med. 2017; 127(5): 352-360, doi: 10.20452/pamw.3985, indexed in Pubmed: 28400547.

13. Wopereis DM, Du Puy RS, van Heemst D, et al. Thyroid Studies Collaboration. The Relation Between Thyroid Function and Anemia: A Pooled Analysis of Individual Participant Data. J Clin Endocrinol Metab. 2018; 103(10): 3658-3667, doi: 10.1210/ jc.2018-00481, indexed in Pubmed: 30113667.

14. Sengupta S, Jaseem T, Ambalavanan J, et al. Homeostatic Model Assessment-Insulin Resistance (HOMA-IR 2) in Mild Subclinical Hypothyroid Subjects. Indian J Clin Biochem. 2018; 33(2): 214-217, doi: 10.1007/s12291-017-0647-4, indexed in Pubmed: 29651214.

15. Chang YC, Hua SC, Chang CH, et al. High TSH Level within Normal Range Is Associated with Obesity, Dyslipidemia, Hypertension, Inflammation, Hypercoagulability, and the Metabolic 
Syndrome: A Novel Cardiometabolic Marker. J Clin Med. 2019; 8(6), doi: 10.3390/jcm8060817, indexed in Pubmed: 31181658.

16. Kim D, Vazquez-Montesino LM, Escober JA, et al. Low Thyroid Function in Nonalcoholic Fatty Liver Disease Is an Independent Predictor of All-Cause and Cardiovascular Mortality. Am J Gastroenterol. 2020; 115(9): 1496-1504, doi: 10.14309/ ajg.0000000000000654, indexed in Pubmed: 32496342.

17. Kim D, Kim W, Joo SK, et al. Subclinical Hypothyroidism and Low-Normal Thyroid Function Are Associated With Nonalcoholic Steatohepatitis and Fibrosis. Clin Gastroenterol Hepatol. 2018; 16(1): 123-131.e1, doi: 10.1016/j.cgh.2017.08.014, indexed in Pubmed: 28823829.

18. Desideri G, Bocale R, D’Amore AM, et al. Thyroid hormones modulate uric acid metabolism in patients with recent onset subclinical hypothyroidism by improving insulin sensitivity. Intern Emerg Med. 2020; 15(1): 67-71, doi: 10.1007/s11739019-02065-9, indexed in Pubmed: 30868444.

19. Patil VP, Shilpasree AS, Patil VS, et al. Evaluation of renal function in subclinical hypothyroidism. J Lab Physicians. 2018; 10(1): 50-55, doi: 10.4103/JLP.JLP_67_17, indexed in Pubmed: 29403205.

20. Tuliani TA, Shenoy M, Belgrave K, et al. Role of Microalbuminuria in Predicting Cardiovascular Mortality in Individuals With Subclinical Hypothyroidism. Am J Med Sci. 2017; 354(3): 285-290, doi: 10.1016/j.amjms.2017.04.022, indexed in Pubmed: 28918836.

21. Kolesnikova OV, Radchenko AO. [Modern view on the mechanisms of oxidative stress and its biomarkers in a larger number of non-communicable diseases]. Ukrain Therap J. 2020; 1: 51-61, doi: 10.30978/UTJ2020-1-51.

22. Radchenko A, Kolesnikova O. Assessment of oxidative status and inflammation in patients with arterial hypertension and subclinical hypothyroidism and their relationship to aging rates. Ukrain Therap J. 2021(2), doi: 10.30978/utj2021-2-21.

23. Shalimova A, Psarova V, Kochuieva M, et al. Features of hemodynamic and metabolic disorders in obese patients with resistant hypertension. Arterial Hypertension. 2020; 24(1): 22-29, doi: 10.5603/ah.a2020.0002.

24. Tellechea ML. Meta-analytic evidence for increased low-grade systemic inflammation and oxidative stress in hypothyroid patients. Can levothyroxine replacement therapy mitigate the burden? Endocrine. 2021; 72(1): 62-71, doi: 10.1007/s12020020-02484-1, indexed in Pubmed: 32880055.

25. Zhang W, Huang Q, Zeng Z, et al. Sirt1 Inhibits Oxidative Stress in Vascular Endothelial Cells. Oxid Med Cell Longev. 2017; 2017: 7543973, doi: 10.1155/2017/7543973, indexed in Pubmed: 28546854.

26. Yamamoto M, Takahashi Y. The Essential Role of SIRT1 in Hypothalamic-Pituitary Axis. Front Endocrinol (Lausanne). 2018; 9: 605, doi: 10.3389/fendo.2018.00605, indexed in Pubmed: 30405528.

27. Garg O, salam A, Singh S, et al. Correlation Between TSH and Body Mass Index in Male and Female Patients with Subclinical Hypothyroidism. Era's J Med Res. 2018; 5(2): 94-98, doi: 10.24041/ejmr2018.72.

28. Mulic M, Muminovic S, Skrijelj F, et al. The importance of anthropometric parameters in patients with subclinical hy- pothyroidism. SANAMED. 2018; 13(1): 23, doi: 10.24125/ sanamed.v13i1.200.

29. Tykarski A, Filipiak K, Januszewicz A, et al. 2019 Guidelines for the Management of Hypertension - Part 1-7. Arterial Hypertension. 2019; 23(2): 41-87, doi: 10.5603/ah.a2019.0008.

30. Prejbisz A, Dobrowolski P, Kosiński P, et al. Management of hypertension in pregnancy - prevention, diagnosis, treatment and long-term prognosis. A position statement of the Polish Society of Hypertension, Polish Cardiac Society and Polish Society of Gynaecologists and Obstetricians. Arterial Hypertension. 2019; 23(3): 117-182, doi: 10.5603/ah.a2019.0011.

31. Rahman S, Islam S, Haque T, et al. Association between serum liver enzymes and hypertension: a cross-sectional study in Bangladeshi adults. BMC Cardiovasc Disord. 2020; 20(1): 128, doi: 10.1186/s12872-020-01411-6, indexed in Pubmed: 32160872.

32. Tsuda K. Red blood cell abnormalities and hypertension. Hypertens Res. 2020; 43(1): 72-73, doi: 10.1038/s41440-019-0353-0, indexed in Pubmed: 31666713.

33. Chang CH, Yeh YC, Caffrey JL, et al. Metabolic syndrome is associated with an increased incidence of subclinical hypothyroidism - A Cohort Study. Sci Rep. 2017; 7(1): 6754, doi: 10.1038/ s41598-017-07004-2, indexed in Pubmed: 28754977.

34. Guo W, Li X, Wu J, et al. Serum alkaline phosphatase is associated with arterial stiffness and 10-year cardiovascular disease risk in a Chinese population. Eur J Clin Invest. 2021; 51(8): e13560, doi: 10.1111/eci.13560, indexed in Pubmed: 33846986.

35. Avolio AP, Kuznetsova T, Heyndrickx GR, et al. Arterial Flow, Pulse Pressure and Pulse Wave Velocity in Men and Women at Various Ages. Adv Exp Med Biol. 2018; 1065: 153-168, doi: 10.1007/978-3-319-77932-4_10, indexed in Pubmed: 30051383.

36. Yoon H, Lee JHo, Kim GS, et al. The relationship between anemia and pulse pressure and hypertension: The Korea National Health and Nutrition Examination Survey 2010-2012. Clin Exp Hypertens. 2018; 40(7): 650-655, doi: 10.1080/10641963.201 7.1416123, indexed in Pubmed: 29319360.

37. Saladini F, Mos L, Fania C, et al. P5467Gender related differences in the clinical significance of elevated pulse pressure in the young. Results from the HARVEST study. Eur Heart J. 2019; 40(Suppl_1), doi: 10.1093/eurheartj/ehz746.0421.

38. Lee J, Ha J, Jo K, et al. Male-specific association between subclinical hypothyroidism and the risk of non-alcoholic fatty liver disease estimated by hepatic steatosis index: Korea National Health and Nutrition Examination Survey 2013 to 2015. Sci Rep. 2018; 8(1): 15145 , doi: $10.1038 / s 41598-018-32245-0$, indexed in Pubmed: 30310098.

39. Tsou MT. Subclinical Hypothyroidism Represents Visceral Adipose Indices, Especially in Women With Cardiovascular Risk. J Endocr Soc. 2021; 5(6): bvab028, doi: 10.1210/jendso/bvab028, indexed in Pubmed: 34017932.

40. Deng L, Wang L, Zheng X, et al. Women with Subclinical Hypothyroidism are at Higher Prevalence of Metabolic Syndrome and Its Components Compared to Men in an Older Chinese Population. Endocr Res. 2021 [Epub ahead of print]: 1-10, doi: 10.1080/07435800.2021.1928177, indexed in Pubmed: 34028317. 